\title{
Chromatography-Olfactometry Study of the Aroma of Fino Sherry Wines
}

\author{
L. Zea, L. Moyano, M. J. Ruiz, and M. Medina \\ Department of Agricultural Chemistry, University of Cordoba, Campus de Rabanales, edificio Marie Curie, 14014 Cordoba, Spain \\ Correspondence should be addressed to L. Moyano, qe1mocal@uco.es
}

Received 9 March 2010; Revised 21 May 2010; Accepted 7 June 2010

Academic Editor: Bogusław Buszewski

Copyright $\odot 2010$ L. Zea et al. This is an open access article distributed under the Creative Commons Attribution License, which permits unrestricted use, distribution, and reproduction in any medium, provided the original work is properly cited.

The aroma of Fino sherry wines produced by industrial biological aging for 0, 1.5, 2.5, 4.5, and 6 years in the Montilla-Moriles region (southern Spain) was studied by gas chromatography-olfactometry. The aroma sensations detected by 3 trained sniffers were classified according to their odor descriptors into 8 odorant series (fruity, empyreumatic, chemical, fatty, balsamic, vegetable, floral, and spicy), describing the aroma profile of the studied wines. The results showed 47 detected odors in the unaged wines, 50 in the 1.5-years-old wines and 59, 61 and 69 in the wines aged 2.5, 4.5, and 6 years, respectively. According to the frequency of the perceived aromas, the fruity and empyreumatic series were the most characteristic odorant series. By exception of chemical, floral and balsamic series without changes during aging of the wines, the remainder series increased their participation during the aging, mainly the fruity, empyreumatic, and fatty series.

\section{Introduction}

Sherry-type white wine called "Fino" is obtained through a long process (about 5-6 years) of biological aging under the action of so-called flor yeasts, which develop aerobically on the surface of wines containing $15-15.5 \%$ ethanol $[1,2]$. Fino wine exhibits special sensory features including a pale yellow color, a slightly bitter flavor and a complex aroma. This last is developed during its biological aging, largely as a result of the action of flor yeasts as well as the contribution of volatile compounds extracted from the wood casks where the wine is aged. In addition, flor yeasts protect the wine from chemical browning, preserving its pale color throughout the aging period [3], and the contact of the wine with cask wood causes some of its components to be extracted, acquiring the wine its characteristic bouquet.

Essentially, the industrial aging method used in the area involves storing the wine in $500 \mathrm{~L}$ American oak barrels which are stacked in rows called escalas to construct a criaderas and solera system. The barrels in each escala contain the same wine at the same aging stage. The first escala, called solera, is closest to the ground and contains the oldest wine. A fraction from $1 / 3$ to $1 / 4$ of its contents is withdrawn 3-4 times a year for bottling. After each withdrawal, the barrels in the solera are replenished with wine from the second escala, also called first criadera, which in turn is replenished with wine from the third escala (second criadera) and so forth. The topmost escala, contains young wine from the year's vintage.

The aroma profile of wine is rather complex. In fact, some analytical techniques such as GC-MS have allowed the identification of more than eight hundred volatile compounds. Many, however, are present at very low concentration levels [4]. In any case, instrumental techniques can detect chemicals, but are unable to identify those with a perceivable odor; in fact, only a small number of volatile compounds are odor active and contributors to wine aroma [5-8].

Gas chromatography-olfactometry (GC-O), also known as "sniffing", is highly useful for establishing aroma profiles as it allows the discrimination of odor-active compounds in complex matrices [9-14]. In some cases, this discriminating ability is more than adequate; in most, however, the specific contribution of each individual odor compound to the overall aroma must be established. To this end, the GC-O has increasingly been used in combination with sophisticated olfactometric methods to estimate the sensory contribution of odor active compounds [15-17]. 
In this work, changes in odor descriptors during biological aging of Fino sherry wines are studied with a view to estimating their different participation in the aroma profile and to establish the sequence of the odorant series which constitute the aroma fingerprint of these wines.

\section{Material and Methods}

Very pale sherry wines (fino type), selected by expert tasters as more representatives among the wines produced in 21 cellars from Montilla-Moriles region, were used. The wines were biologically aged for 0 (young wine), 1.5, 2.5, 4.5, and 6 years. This last wine is commercially considered as highquality typical fino sherry wines. One sample for each aging year (or escala) was taken of each cellar. All wines of the same aging degree were mixed and immediately analyzed by triplicate.

The identification of each aroma compound was carried out by its retention time, coelution with a standard (purity $>99 \%$, Sigma Aldrich, Munich, Germany), and Mass Spectrometry (Hewlett-Packard 5972 MSD, CA, USA). The conditions of MS were scan mode and mass range from 39 to $300 \mathrm{amu}$. The chromatographic column, injector and oven temperatures, carrier gas and its flow were the same that those used for the sniff, being described below.

Samples of $100 \mathrm{~mL}$ of wine were adjusted to $\mathrm{pH} 3.5$, $150 \mu \mathrm{g}$ of 2 -octanol was added as an internal standard and then extracted with $100 \mathrm{~mL}$ of freon-11 (Sigma-Aldrich Quimica, S.A., Madrid, Spain) in a continuous extractor for 24 hours (liquid-liquid extractor for use with solvents with higher density than sample). After concentration of the freon extracts to $0.2 \mathrm{~mL}$ in a micro-Kuderna-Danish concentrator, the GC-O analyses were carried out in a Hewlett-Packard-5890 series II gas chromatograph equipped with a sniffing port (Olfactory Detector, part. No. 093500, SGE-International, Australia) connected by a flow splitter to the column exit. The GC effluent was split $1: 2$ between the FID and the sniffing port. Humidified air was added in the sniffing port at $33 \mathrm{~mL} / \mathrm{min}$. Three microliters were injected into the chromatograph equipped with a HP-INNOWax column of $60 \mathrm{~m} \times 0.32 \mathrm{~mm} \times 0.25 \mu \mathrm{m}$ thickness (Agilent Technology, CA, USA). The oven temperature program was as follows: $5 \mathrm{~min}$ at $45^{\circ} \mathrm{C}, 1^{\circ} \mathrm{C} / \mathrm{min}$ up to $185^{\circ} \mathrm{C}$, and $30 \mathrm{~min}$ at $185^{\circ} \mathrm{C}$. Injector and detector temperatures were $275^{\circ} \mathrm{C}$ and $300^{\circ} \mathrm{C}$, respectively. The carrier gas was helium at $70 \mathrm{kPa}$ and split $1: 30$.

Three trained judges, one woman and two men, selected for their ability to generate accurate terms as well as experienced in CG-O Sherry wines, performed the sniffing of the extracts. The panelists took turns for 15 minutes and again up to 140 minutes (total time of aromagram). Samples were sniffed three times, of same way previously mentioned, one session per day, and aroma descriptors and approximate times were recorded.

\section{Results and Discussion}

Table 1 shows the results of the GC-O analysis of the wine during the biological aging. Based on the high complexity of the odor profile, some compounds may be associated to two or three different notes $[18,19]$. As in previous work, the most common odor descriptors were classified into aroma series in order to reduce the number of variables to be interpreted in establishing the aroma profile for the wines $[1,20]$.

The sniffers detected a total of 47, 50, 59, 61, and 69 different odors in wine from the fifth, fourth, third, second, and first cask row (escala), respectively. This suggests that aroma perceptions increase as the wine ages. The odors are grouped in three odorant zones (OZs) defined between two retention times $\left(R_{t}\right)$ for each and separated by a gap of at least $6 \mathrm{~min}$ with no odor perception. Thus, $\mathrm{OZ}_{1}$ spanned the aromagram region from 8.5 to $46.1 \mathrm{~min}, \mathrm{OZ}_{2}$ from 57.8 to $64.6 \mathrm{~min}$ and $\mathrm{OZ}_{3}$ from 73.5 to $136.7 \mathrm{~min}$. As can be seen in Table 1, the first and third zones were the most useful in sensory terms as they jointly accounted for more than $90 \%$ of total aroma notes detected in all escalas, whereas the second zone accounted for only about $10 \%$ of such notes.

Taking into account the citation frequency that an odor associated to a given aroma series was detected, it can be observed that $\mathrm{OZ}_{1}$ for fino wines was characterized largely by fruity series, followed by chemical and fatty series. Empyreumatic, vegetable, floral and balsamic odors were less frequently detected, and spicy notes were never detected, in this zone.

The fruity odors perceived (strawberry, apple, pineapple, peach, overripe melon, banana and almond) were all due to acetaldehyde and its derivative 1,1-diethoxyethane in addition to ethyl acetate, isobutanoate, butanoate, hexanoate, lactate, and octanoate, isoamyl acetate and an unidentified compound with $R_{t}=13.0 \mathrm{~min}$. The number of fruity notes in $\mathrm{OZ}_{1}$ remained constant during the biological aging process; however, banana note was only detected in wine from the fifth and fourth escalas rows ( 0 and 1.5 years old, resp.); also, overripe melon notes were only detected in the third, second, and first escalas (2.5, 4.5 and 6 years old, resp.).

The descriptors associated to the fatty series detected in $\mathrm{OZ}_{1}$ included butter, cookie, and cheese. All were detected in every escala and due to the presence of 2,3-butanedione, methyl butanoate, acetoin and ethyl lactate throughout the aging process. This was also the case with the varnish, glue, alcohol, nail polish, vinous, and solvent odors, all in the chemical series, which were due to the presence of ethyl acetate, methyl butanoate, isobutanol, and isoamyl alcohols.

Empyreumatic odors were much less frequently detected than were those grouped in the previous series. This series included toasted notes in wine from the fifth to the second escalas due to an unidentified compound with $R_{t}=22 \mathrm{~min}$. However, the first escala ( 6 years) exhibited a greater variety of empyreumatic notes including chocolate, coffee, toasted and burnt wood, the first three of which were due to unidentified compounds with retention times from 8.9 to $15 \mathrm{~min}$ and the last to furfural. The only vegetable (herbaceous) odor identified by the sniffers was detected below the third escala (2.5 years of aging) and due to octanal. Also, the only floral note was detected below the second escala and due to furfural. Finally, the sole balsamic (liqueur) odor detected was found in the youngest wine (fifth escala) 
TABLE 1: Retention time, odor descriptors, and odorant series of the compounds detected by the sniffers grouped in three odorant zones (OZ).

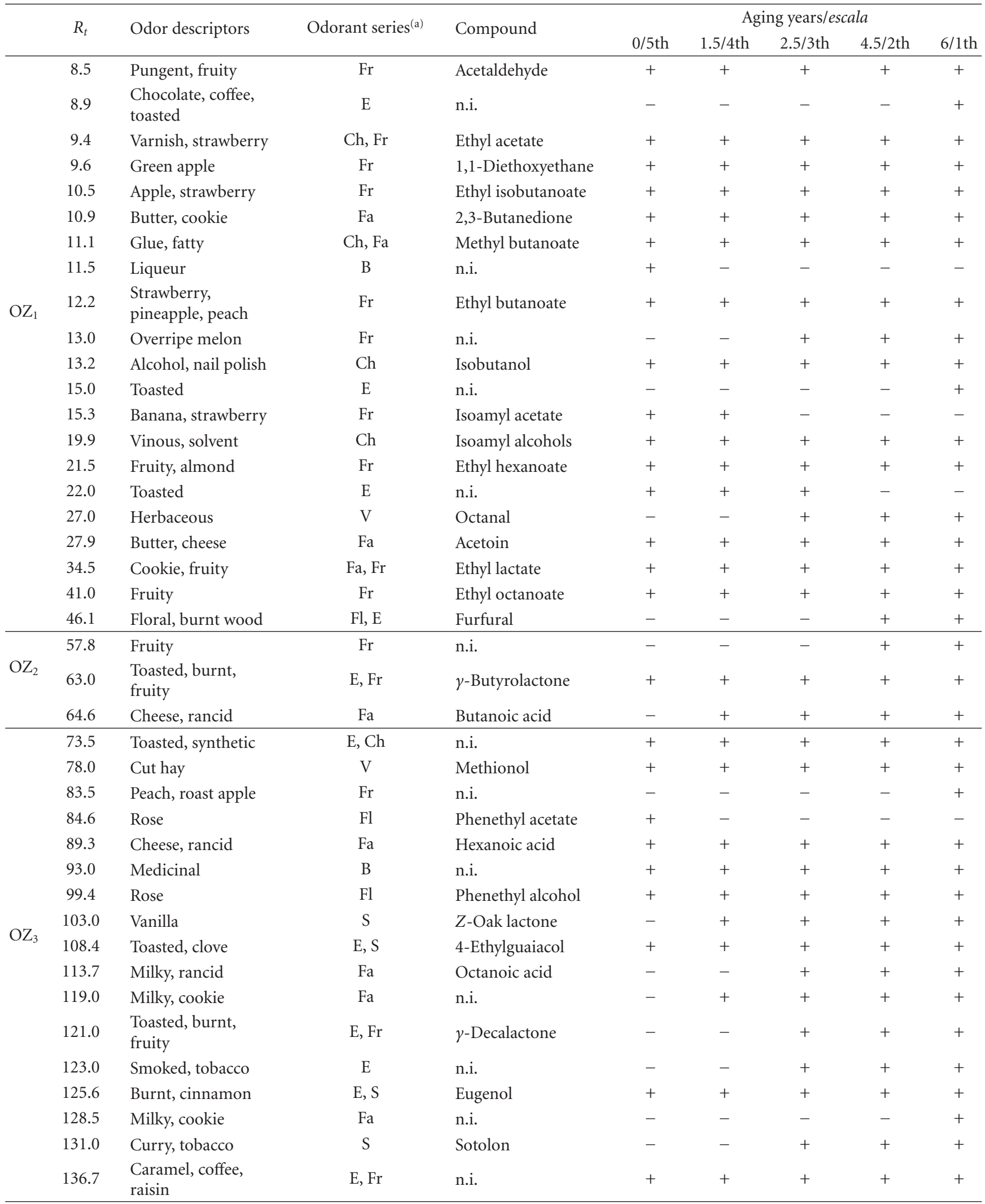

(a) Fr: fruity; E: empyreumatic; Ch: chemical; Fa: fatty; B: balsamic; V: vegetable; Fl: floral; S: spicy n.i.: not identified.

The "+" indicates that sensation was detected by at least two sniffers and the "-" when the odor was detected only by one or none sniffers. 
and due to the presence of an unidentified compound with $R_{t}=11.5 \mathrm{~min}$.

As noted earlier, the $\mathrm{OZ}_{2}$ was the smallest contributor to the aroma profile of the studied wines. In fact, it only encompassed odors in the fruity, empyreumatic and fatty series. Fruity notes were due to an unidentified compound with $R_{t}=57.8 \mathrm{~min}$ and $\gamma$-butyrolactone; none, however, was ascribed to a specific fruit. The number of fruity notes detected in this zone remained constant to the third escala ( 2.5 years) and then increased by effect of the contribution of the above-mentioned unidentified compound detected in the wines aged 4.5 years or more. The aroma notes associated to the empyreumatic (toasted, burnt) and fatty series (cheese, rancid) were due to $\gamma$-butyrolactone and butanoic acid, respectively, which remained practically constants throughout the aging period.

The odors in $\mathrm{OZ}_{3}$ were mostly related to the empyreumatic, spicy, fruity, and fatty series. The toasted, burnt, caramel, and coffee notes detected in wine from the fifth and fourth escalas ( 0 and 1.5 years old, respectively) were associated to two unidentified compounds with a retention time of 73.5 and $136.7 \mathrm{~min}$, respectively, in addition to 4-ethylguaiacol and eugenol. Empyreumatic odors were stronger in the third and lower escalas by effect of the presence of toasted, burnt ( $\gamma$-decalactone), smoked, and tobacco notes- the two lasts was due to an unidentified compound with $R_{t}=123.0 \mathrm{~min}$.

The spicy notes detected in $\mathrm{OZ}_{3}$ included vanilla $(Z$-oak lactone), clove (4-ethylguaiacol), cinnamon (eugenol), and curry (sotolon). Clove and cinnamon odors were detected throughout the wine aging period, whereas vanilla odors were first detected in the fourth escala (1.5 years old wine) and curry odors in the third (2.5 years of aging) - hence spicy notes strengthened with aging of the wine.

The fruity aromas in $\mathrm{OZ}_{3}$ were described as peach, roast apple, and raisin, and due to two unidentified compounds with a retention time of 83.5 and $136.7 \mathrm{~min}$, respectively, and also as unspecified fruity odors ( $Z$-oak lactone and $\gamma$-decalactone). The fruity notes in $\mathrm{OZ}_{3}$ are increased substantially during aging of the wine. Thus, the youngest wine (fifth escala) only exhibited raisin notes, whereas that in the fourth escala additionally exhibited the fruity odor of $Z$-oak lactone; the third and second of $\gamma$-decalactone; and the first of peach and roast apple. The cheese, rancid, milky, and cookie notes in the fatty series were due to hexanoic and octanoic acids in addition to two unidentified compounds with a retention time of 119.0 and $128.5 \mathrm{~min}$, respectively. Like fruity notes, these odors grew during aging of the wine, largely by effect of the gradual increase in milky notes.

The floral, chemical, vegetable, and balsamic notes were smaller contributors to $\mathrm{OZ}_{3}$; in fact, they only contributed a single note to each and their strength remained constant throughout the wine aging period. The detected odors included rose (phenethyl alcohol and its acetate), synthetic (unidentified compound with $R_{t}=73.5 \mathrm{~min}$ ), cut hay (methionol), and medicinal (unidentified compound with $\left.R_{t}=93.0 \mathrm{~min}\right)$.

In order to show the total aroma notes of fino wine at various escalas of its biological aging, the odor descriptors

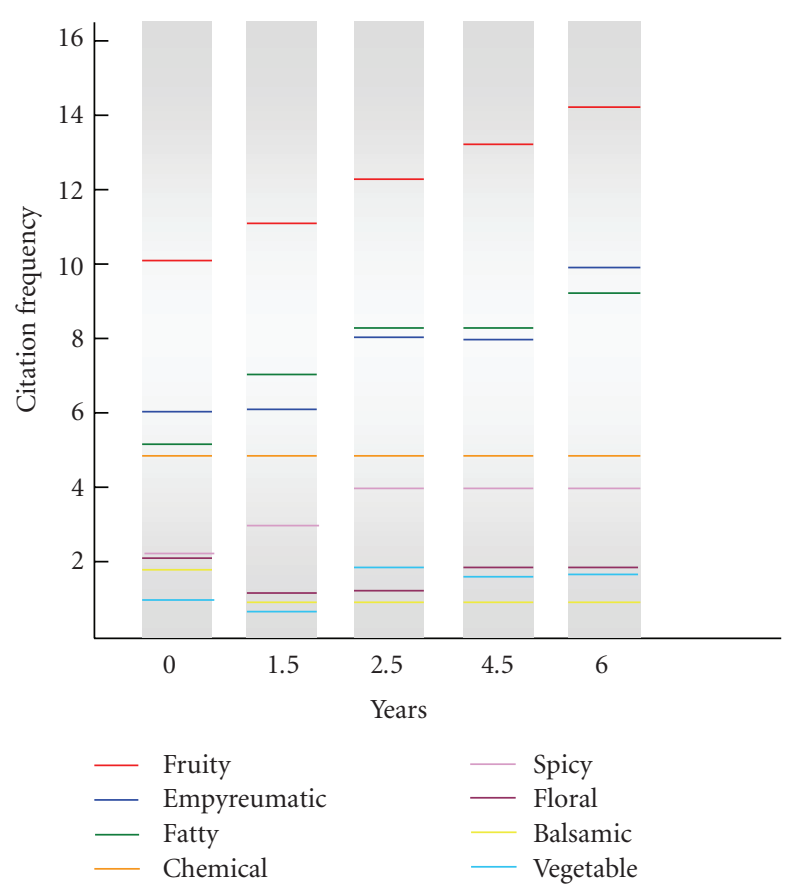

FIGURE 1: Aroma fingerprint for sherry type wine during the biological aging.

for each one were arranged in increasing order of number of detections of the different aroma series (Figure 1). As can be seen, the highest citation frequency was the fruity series, which was that contributing the largest number of odor notes to the sensory profile of the wine throughout the aging process. Next came the empyreumatic and fatty series, followed by the chemical and spicy series, and, finally, the floral, balsamic and vegetable series. It should be noted that this sequence of series, which could constitute the aroma fingerprint of the wine, remained unchanged throughout the aging period; by exception, the fatty, vegetable and empyreumatic series exhibited slight changes in some escalas related to an increased contribution to the aroma of the wine.

In summary, the results of the GC-O analysis carried out during the aging of Fino wine revealed that all odorant series grew according to the citation frequency (particularly the fruity, empyreumatic and fatty ones) with time. By exception, the chemical, floral, and balsamic ones exhibited practically a constant contribution to the wine aroma throughout the aging process. Therefore, the compounds grouped in those series can be deemed the greatest contributors to the changes in aroma fingerprint during the biological aging of sherry wines.

\section{Acknowledgment}

This paper was supported by a grant from the Andalusian Government (Spain), Reference AGR-767. 


\section{References}

[1] L. Zea, L. Moyano, J. A. Moreno, and M. Medina, "Aroma series as fingerprints for biological ageing in fino sherry-type wines," Journal of the Science of Food and Agriculture, vol. 87, no. 12, pp. 2319-2326, 2007.

[2] R. Peinado and J. Mauricio, "Biologically aged wines," in Wine Chemistry and Biochemistry, pp. 81-96, Springer, New York, NY, USA, 2009.

[3] R. Barón, M. Mayén, J. Mérida, and M. Medina, "Changes in phenolic compounds and browning during biological aging of sherry-type wine," Journal of Agricultural and Food Chemistry, vol. 45, no. 5, pp. 1682-1685, 1997.

[4] C. Bayonove, R. Baumes, J. Crouzet, and Z. Gunata, "Aromas," in Enología: Fundamentos Científicos y Tecnológicos, pp. 137176, AMV-Mundi Prensa, Madrid, Spain, 2000.

[5] V. Ferreira, R. López, and J. F. Cacho, "Quantitative determination of the odorants of young red wines from different grape varieties," Journal of the Science of Food and Agriculture, vol. 80, no. 11, pp. 1659-1667, 2000.

[6] Y. Kotseridis and R. Baumes, "Identification of impact odorants in Bordeaux red grape juice, in the commercial yeast used for its fermentation, and in the produced wine," Journal of Agricultural and Food Chemistry, vol. 48, no. 2, pp. 400-406, 2000.

[7] R. López, N. Ortín, J. P. Pérez-Trujillo, J. Cacho, and V. Ferreira, "Impact odorants of different young white wines from the Canary Islands," Journal of Agricultural and Food Chemistry, vol. 51, no. 11, pp. 3419-3425, 2003.

[8] L. Zea, L. Moyano, and M. Medina, "Odorant active compounds in Amontillado wines obtained by combination of two consecutive ageing processes," European Food Research and Technology, vol. 227, no. 6, pp. 1687-1692, 2008.

[9] W. Grosch, "Evaluation of the key odorants of foods by dilution experiments, aroma models and omission," Chemical Senses, vol. 26, no. 5, pp. 533-545, 2001.

[10] A. Mayol and T. Acree, "Advances in gas chromatographyolfactometry," in Gas Chromatography-Olfactometry, J. Leland, P. Schierberle, A. Buettner, and T. Acree, Eds., pp. 1-10, The state of the art, Washington, DC, USA, 2001.

[11] E. Campo, V. Ferreira, A. Escudero, J. C. Marqués, and J. Cacho, "Quantitative gas chromatography-olfactometry and chemical quantitative study of the aroma of four Madeira wines," Analytica Chimica Acta, vol. 563, no. 1-2, pp. 180-187, 2006.

[12] M. J. Gómez-Míguez, J. F. Cacho, V. Ferreira, I. M. Vicario, and F. J. Heredia, "Volatile components of Zalema white wines," Food Chemistry, vol. 100, no. 4, pp. 1464-1473, 2007.

[13] B. Plutowska and W. Wardencki, "Application of gas chromatography-olfactometry (GC-O) in analysis and quality assessment of alcoholic beverages-a review," Food Chemistry, vol. 107, no. 1, pp. 449-463, 2008.

[14] J. Dharmawan, S. Kasapis, P. Sriramula, M. J. Lear, and P. Curran, "Evaluation of aroma-active compounds in Pontianak orange peel oil (Citrus nobilis Lour. var. microcarpa Hassk.) by gas chromatography-olfactometry, aroma reconstitution, and omission test," Journal of Agricultural and Food Chemistry, vol. 57, no. 1, pp. 239-244, 2009.

[15] Y. Fang and M. Qian, "Aroma compounds in Oregon Pinot Noir wine determined by aroma extract dilution analysis (AEDA)," Flavour and Fragrance Journal, vol. 20, no. 1, pp. 2229, 2005.

[16] O. Gürbüz, J. M. Rouseff, and R. L. Rouseff, "Comparison of aroma volatiles in commercial Merlot and Cabernet Sauvi- gnon wines using gas chromatography-olfactometry and gas chromatography-mass spectrometry," Journal of Agricultural and Food Chemistry, vol. 54, no. 11, pp. 3990-3996, 2006.

[17] B. D’Acampora Zellner, P. Dugo, G. Dugo, and L. Mondello, "Gas chromatography-olfactometry in food flavour analysis," Journal of Chromatography A, vol. 1186, no. 1-2, pp. 123-143, 2008.

[18] M. Cliff, D. Yuksel, B. Girard, and M. King, "Characterization of Canadian ice wines by sensory and compositional analyses," American Journal of Enology and Viticulture, vol. 53, no. 1, pp. 46-53, 2002.

[19] S. M. Rocha, F. Rodrigues, P. Coutinho, I. Delgadillo, and M. A. Coimbra, "Volatile composition of Baga red wine: assessment of the identification of the would-be impact odourants," Analytica Chimica Acta, vol. 513, no. 1, pp. 257262, 2004.

[20] L. Moyano, L. Zea, L. Villafuerte, and M. Medina, "Comparison of odor-active compounds in sherry wines processed from ecologically and conventionally grown Pedro Ximenez grapes," Journal of Agricultural and Food Chemistry, vol. 57, no. 3, pp. 968-973, 2009. 


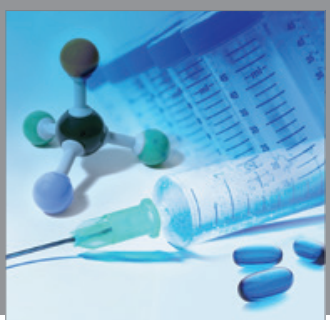

International Journal of

Medicinal Chemistry

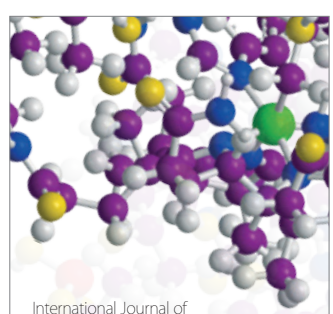

Carbohydrate Chemistry

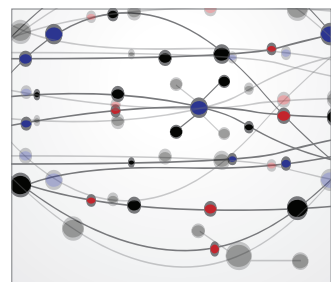

The Scientific World Journal
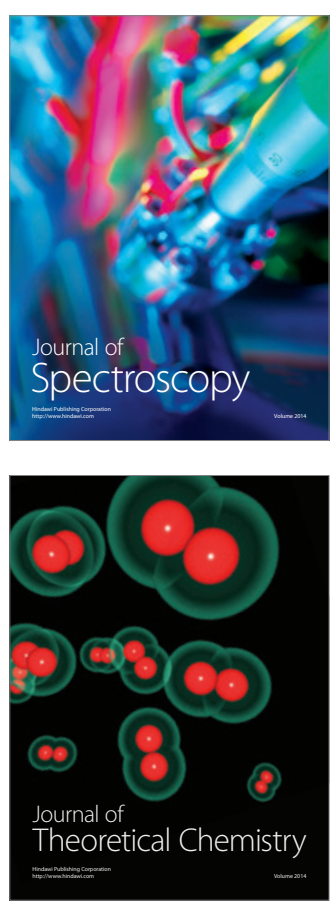
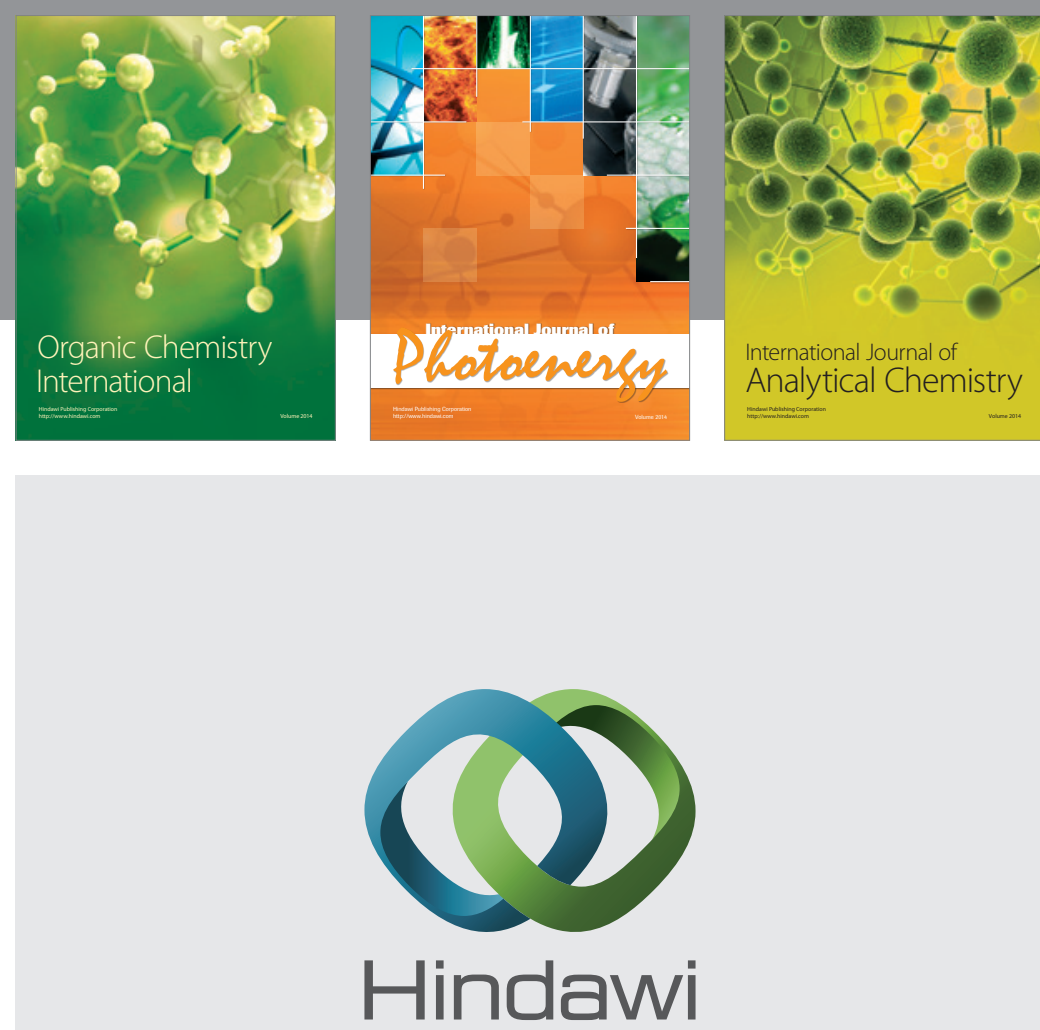

Submit your manuscripts at

http://www.hindawi.com
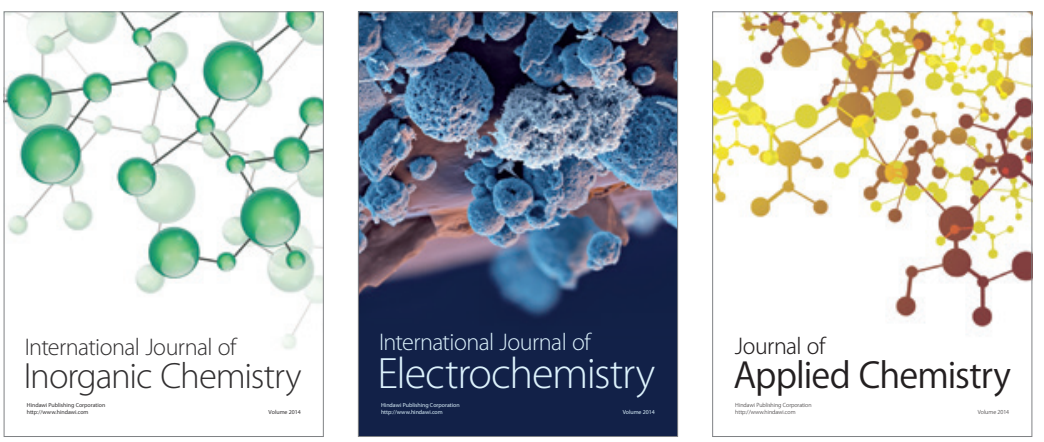

Journal of

Applied Chemistry
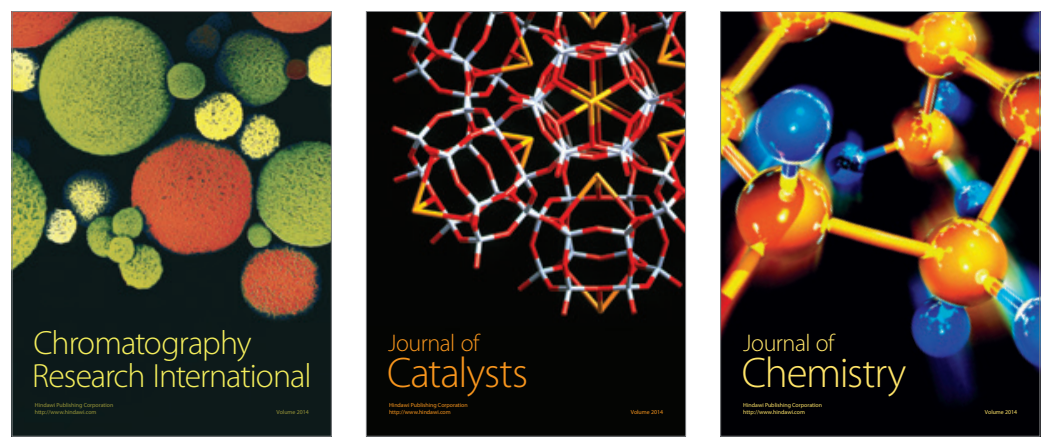
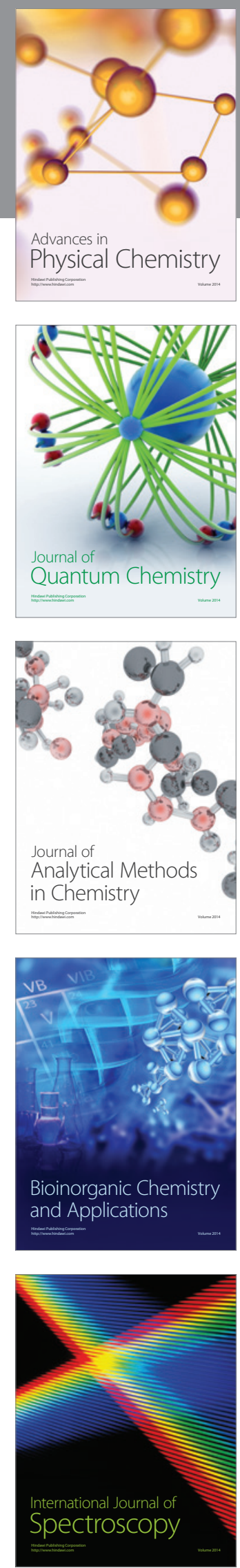